\title{
Aisthesis
}

Firenze University Press

www.fupress.com/aisthesis

OPEN ACCESS

Citation: L. Filieri (2021) Kant on the Purposiveness of the Reflecting Power of Judgment. Aisthesis 14(2): 29-40. doi: 10.36253/Aisthesis-12786

Copyright: (c) 2021 L. Filieri. This is an open access, peer-reviewed article published by Firenze University Press (http://www.fupress.com/aisthesis) and distributed under the terms of the Creative Commons Attribution License, which permits unrestricted use, distribution, and reproduction in any medium, provided the original author and source are credited.

Data Availability Statement: All relevant data are within the paper and its Supporting Information files.

Competing Interests: The authors have declared that no competing interests exist.

\section{Kant on the Purposiveness of the Reflecting Power of Judgment}

\author{
LUIGI FILIERI \\ Johannes Gutenberg-Universität Mainz (Germany) \\ lfilieri@uni-mainz.de
}

\begin{abstract}
In this paper I argue that 1) Kant's power of judgment is constitutively always reflecting, as its lawful employments involve a preliminary self-reference of the faculties the power of judgment itself is required to connect and let them match with each other. Accordingly, I claim that 2) the principle of purposiveness is the principle of the power of judgment as such, and not just of an allegedly self-standing reflecting branch of this faculty. I criticize the view that Kant draws a dichotomy between reflecting and determining judgments and argue that 3) Kant's point in the third Critique is to rule out the amphiboly between the reflecting and the determining employment of the principle of purposiveness. The power of judgment is, as such, always reflecting: while in the case of cognition it also works in a determining way, in the case of both aesthetics and teleology it is only reflecting, i.e., self-purposive - as it sets its function as its own end.
\end{abstract}

Keyworkds: Purposiveness, Reflecting Judgment, Self-Reference, Aesthetics, Teleology.

\section{FINALISM AND REFLECTING JUDGMENTS}

The idea of a reflecting power of judgment is one of the most distinctive marks of Kant's third Critique ${ }^{1}$. Reflecting judgments open a new path towards the systematic unity of nature, as they follow from the transcendental principle of the power of judgment. The principle of purposiveness at once strengthens the importance of the regulative function of the ideas of reason in the first Critique and further develops Kant's account of the systematic unity of all cognitions. Moreover, only as reflecting the power of judgment can lawfully aim to bridge the gap between the domains of nature and freedom (cf. Anceschi [1972]: 184). Finally, recalling one of the main legacies of

\footnotetext{
${ }^{1}$ All quotations follow The Cambridge Edition of the Works of Immanuel Kant: Critique of Pure Reason, (KrV, A B); Critique of the Power of Judgment, (KU, AA 5; EE for the First Introduction, AA 20). The page-numbers from the English translations are always in ().
} 
Kant's third Critique in German Romanticism (cf. Amoroso [2015]), the idea of a reflecting power of judgment grants the possibility of aesthetic judgments of taste.

While it is indisputable that these achievements follow from Kant's account of a reflecting power of judgment, it may be not immediately clear why do we need a specification for the power of judgment when the third Critique explicitly deals with the power of judgment in general. One may also doubt whether Kant's account of the power of judgment needs two at least autonomous functions - a determining and a reflecting one. Another relevant question concerns the principle of purposiveness itself. Why does Kant state that the latter is the principle of the reflecting power of judgment? On the one hand, one may answer that the power of judgment ought to have its own principle if it has to count among the faculties of reason. Without a principle, the power of judgment could not aim to attain its main goal, namely bridging the gap between nature and freedom. This first answer makes it clearer that the power of judgment needs its own principle, yet it does not explain why it has to be the principle of purposiveness. On the other hand, dealing with this lack of explanation more specifically, one may ask further why the principle of purposiveness alone is entitled to play the role of the principle of the reflecting power of judgment.

Kant argues that the idea of a purposive system of natural laws is the key to our understanding of nature itself, for the systematic unity of nature mirrors reason's need for its own systematic unity. However, raising one last question, one may still ask why the principle of purposiveness did not seemingly serve the determining power of judgment as well - since 1) this principle is the principle of the power of judgment in general; 2) determination is the sole judgmental function with which we have been explicitly dealing in the first Critique. After all, already in the first Critique [KrV, A 643-644 B 671-672 (590-591)] the understanding - our determining function par excellence - had to refer to the regulative and in some sense already purposive function of reason's ideas in order to attain the systematic unity of cognitions (cf. Ferrarin [2015]: 42-57).

According to a first reading, we may sum up Kant's claims in the following way. The dichotomy between the determining and the reflecting power of judgment - which seemingly reiterates one of Kant's most typical methodological habits - follows from the need to grant the possibility of aesthetic evaluation and the teleological arrangement of the empirical laws of nature. Both possibilities indeed require a non-determining employment of the power of judgment (cf. Zuckert [2007]: 66-67). Neither the notion of beauty can be determined - as beauty would then illegitimately count as an empirical concept - nor the finalism we assume in order to overcome the mechanism of nature may translate an objective principle - as it would then be constitutive of nature itself, and not only of our understanding of it. According to this picture, it would make sense to see a full-fledged parallelism. Each branch of the power of judgment - the determining and the reflecting - would then have its own principle: respectively, the principle of the synthetic unity of the apperception and the principle of purposiveness.

Kant himself seems to foster this reading. In section XI of the First Introduction, we read that the notion of a natural end «is used by the power of judgment merely in reflecting, not in determining judgment» [EE, AA 20: 244 (44)]. In section XII, we also read that «it is not the determining but only the reflecting power of judgment that has its own principles [Prinzipien] a priori» [EE, AA 20: 248 (47)]. This idea reaches basically unaltered the published Introduction of the third Critique. In section V, Kant stresses that the finalism we refer to as we apply the «law of the specification of nature» - which follows directly from the principles of purposiveness - «is not a principle of the determining but rather merely of the reflecting power of judgment» $[K U$, AA 5: 186 (72-73)]. According to this picture, Kant established a fullfledged dichotomy between the determining and the reflecting power of judgment. The power of judgment would then entail two different functions: the objective determination of empirical 
concepts; the reflection upon artworks (more precisely, upon their form) and natural formations in accordance with the subjective principle of purposiveness.

This picture also provides us with a specific account of the reflection involved in reflecting judgments. To reflect would then mean to perform a completely different activity than to determine, yet both activities would imply nothing but a reference to things outside there, though according to different aims and outcomes.

The aim of this paper is to show that this seemingly consistent account oversimplifies the relevance and status of the reflection we deal with in reflecting judgments, thereby making it difficult to understand why the power of judgment deserves a transcendental critique. Kant actually "wrote the Critique of Judgment because he aimed to complete what he called his "critical business" the investigation of all knowledge claims involving principles that cannot be justified by experience alone» (Henrich [1992]: 30). Kant's third Critique is not merely «a Critique of the (Reflecting) Power of Judgement, only» (Teufel [2012]: 3). More precisely, we may say that it exclusively deals with the reflecting power of judgment only if we also make it clear that this reflecting status is not just alternative to the determining one. The pillars of a different reading are the following:

- Reflection is the most distinctive and characterizing trait of the power of judgment in general.

- There is a reciprocity between the finalism of the principle of purposiveness and the reflection involved in reflecting judgments.

It is true that a) «determinant and reflective faculties of judgment do not stand to each other as simply parallel functions of a faculty of judgment in general» (Nuzzo [2005]: 166) as it is clear that b) «the Urteilskraft that occupies the third Critique can only be the reflective faculty of judgment" (ibidem). However, I take this second claim b) to mean that the reflecting power of judgment is the power of judgment in its most general and constitutive sense, otherwise it cannot coherently fit with the first claim a).

In her Kant and the Capacity to Judge, Longuenesse ([1998]: 163-167; 195-210) argues that the reflecting power of judgment plays an essential role in the first Critique already, but in her account the reflecting status of reflecting judgments follows from an alleged failure: reflecting judgments are merely reflecting for they produce no concept. This negative account of reflecting judgments (also criticized by Makkreel [2006]) does not take into account the reciprocity between the finalism of the principle of purposiveness and the reflection involved in reflecting judgments. In the following, I aim to show that there is no failure on the side of reflecting judgments, for instead the non-determinacy of the principle of purposiveness is a necessary condition for the power of judgment to achieve two goals that reach further than the mere determination of an empirical concept. Reflecting judgments are no defective version of determining judgments: they mirror the general form of the very activity of the power of judgment in general. To put it short: the power of judgment is reflecting in that it targets its own activity.

The reflecting power of judgment 1 ) is no alternative variant of the determining one (if anything, quite the opposite is true) and 2) does not simply appeal to the principle of purposiveness since it could not count on the fundamental principle of determining judgments - that is the synthetic unity of the apperception. The point is rather that reflecting judgments are reflecting insofar as they are self-purposive. There is no dichotomy between reflection and determination, but rather a hierarchy - for the determining employment of the power of judgment is just one of possible activities of the power of judgment in general - which is intrinsically reflecting (cf. Barale [1992]: 84; Desideri [2003]: 72) and purposively-oriented. Most importantly, the one thing is because of the other.

It is at least misleading to think that the ends of reflecting Judgment's (Urteilskraft) purposiveness are just those we have to assume in order to deal with aesthetic representations or the systematic arrangement of the empirical laws of nature 
- since both require us to appeal to a non-determinable universality. For sure, this is also the case, but the reflecting status of the reflecting power of judgment follows from the fact that the actual end and object of the power of judgment is its own employment (cf. Anceschi [1972]: 196; 199-201). Equally misleading is to think that this self-reference of the power of judgment would not take place in the case of determining judgments or, even worse, to claim that «the determining power of judgement [...] cannot be the subject of a Critique» (Teufel [2012]: 2).

The fundamental difference between determining and reflecting judgments is not that the former may do without a self-purposive reflecting moment - which would then exclusively pertain to the latter. Rather, the determining employment of the power of judgment counts on the objectifying function of the normative framework of the understanding - its pure concepts as rules and the synthetic unity of the apperception - as the means through which we achieve universally valid outcomes. To this regard, it is worth noticing that Garroni ([1998]: 50-53) goes as far as to claim that in the case of determining judgments the power of judgment is but the understanding itself. As Kant himself puts it, in the case of determining judgments the universal is given [KU, AA 5: 179 (66$67)]$. Whenever the universal is not given - as in the case of the universality of the aesthetic feeling of pleasure or the systematic unity of all empirical laws of nature (which cannot be determined by means of objective concepts) - the power of judgment can still target its own activity in order to draw out of itself a principle for its use. It is this self-reference of the power of judgment that which makes sense of its reflecting status, namely its being-its-own-end. In turn, this reflection brings about a purposive order according to which we assume - but not determine - the purposiveness of aesthetic representations and natural formations.

We may define the reflecting employment of the power of judgment in terms of an almost selfreferential activity or, by borrowing Kant's own terminology, as the general heautonomy of the power of judgment (cf. Pollok [2017]: 283-285).
More precisely, the latter notion means that the power of judgment draws a principle out of its own use. If we take this at face value, we may be tempted to think that, in the end, what lies outside this self-reference of the power of judgment is somehow inessential. However, this is not the case. The reflecting employment of the power of judgment is almost, not utterly, self-referential for both in the aesthetic and the teleological case, it finally reaches objects: respectively the form of aesthetic representations and natural formations as such. The point is that, before reaching out of itself, namely towards objects, the power of judgment - as intrinsically reflecting - makes of its own use its end. To reflect is a verb we are thus required to mean quite literally. The power of judgment's needs and aims actually reflect upon the objects of our aesthetic or teleological judgments. In turn, our judging the beautiful forms of nature and art and the teleological structure and development of natural formations mirrors the demands of the power of judgment - as it reflects upon its own use.

The power of judgment - as a reflecting power of judgment - gets always back to itself by assuming as its guide those principles according to which its own employment 1) is lawful, 2) attains the goals of a priori synthesis. From possible experience (by means of the determining use of the categories and the synthetic unity of the apperception), to moral agency (through the categorical imperative) and, finally, the very overarching need for the systematic unity between the two domains of reason. As constitutively reflecting, the power of judgment ought to be its own principle.

\section{THE PRIMACY OF REFLECTION}

By relying on these premises, we gain a different interpretive standpoint on those Kant's statements that one would otherwise misleadingly mean to establish a dichotomy between the reflecting and the determining power of judgment - whereby only the former would work purposively. In section $\mathrm{V}$ of the First Introduction we 
read that to reflect means «to compare and to hold together given representations either with others or with one's faculty of cognition, in relation to a concept thereby made possible» [EE, AA 20: 211 (15)]. On the one hand, this may confirm the dichotomy reading, for reflecting would be simply alternative to determining. However, on the other hand, one may also ask whether it would be possible to compare and to hold together different representations without - as a condition - a preliminary reference of any representation to the faculty of cognition. If we further ask whether we may proceed directly from the faculties of cognition to their objects independently of a preliminary self-purposive reference of the very same faculties upon the principles of their own lawful use, the answer can be but negative. The first Critique already taught us that the concept of nature implies a legislation following from the normative drive of our cognitive faculties [KrV, A 126-129 (241-243); B 163-165 (262-264)]. Kant's point in the Critique of Pure Reason is not to acknowledge how things are, but to state how they ought to be according to a priori principles - in order to be the objects of our possible experience. Said differently, Kant's point is to establish

the autonomy and purposive use of our cognitive faculties in a way that at the same time proves them to involve essentially a reference to the concept (or idea) of a realm of experience that is purposive for the use of our cognitive faculties, i. e. that contains the necessary unity required for their use (Fugate [2014]: 211).

Any reference of a representation to another as well as to the faculties of cognitions implies a preliminary self-reference of the very same faculties, for these make a representation possible in the very first place according to the principles of their lawful use. Kant himself give us a hint when he states that even in the case of a (determining) judgment (Urteil) of experience the power of judgment in its reflection is "also determining" [EE, AA 20: 212 (16), my emphasis].

The power of judgment's need to reiterate its own activity is key. According to an eminently transcendental point of view, it is no matter of how we actually judge, but of how we ought to judge. The principle of purposiveness is the most distinctive mark of the reflection the reflecting power of judgment brings about, for both its purposiveness and reflecting status make it clear that the power of judgment's aims and normative drives are but two sides of the same coin. The power of judgment's ends are the principles of its own use. It makes thus sense to appeal to the principle of purposiveness as to a maxim «as the basis for research into nature» which disregards "what happens" and "how things are judged». It rather works to establish "how they ought to be judged» [KU, AA 5: $182(69)]$. The power of judgment

must thus assume it as an a priori principle for its own use that what is contingent for human insight in the particular (empirical) laws of nature nevertheless contains a lawful unity, not fathomable by us but still thinkable, in the combination of its manifold into one experience possible in itself. [KU, AA 5: 183-184 (70)]

In the guise of a self-reference, the power of judgment is only reflecting, not also determining. It aims to «think of nature [...] in accordance with a principle of purposiveness for our faculty of cognition». The reflecting power of judgment «represents the unique way in which we must proceed in reflection on the objects of nature with the aim of a thoroughly interconnected experience» [KU, AA 5: 184 (71), my emphasis]. Notice that this oughtto-be of the power of judgment requires us to turn the final cause into an efficient one (cf. Allison [2012]: 186). The systematic unity of the empirical laws of nature - an epiphenomenon of reason's own overarching systematic needs - is an end that brings about the conditions and method for its own achievement. Here the drive - the ground is at once the end.

We see that the seeming dichotomy between reflecting and determining Judgment does not hypostatize two heterogeneous and self-standing functions - each allegedly endowed with a particular principle. It rather hides a hierarchy 
between two possible - lawful - employments of the power of judgment.

When Kant stresses that the principle of purposiveness would exclusively belong to the reflecting power of judgment, he could have two different things in mind. On the one hand, if we take his statements at face value, it is hard to deny that we are in front of a dichotomy between two parallel and autonomous employments of the power of judgment. On the other hand, however, if we assume the broader perspective of a critique of the power of judgment, we see that the word reflecting describes the most distinctive mark of the power of judgment as such, that is in its heautonomy, as it sets its own function as its end. Quite a good definition of reflection after all.

The power of judgment may well just proceed only reflectively, but it cannot be merely determining. Any determining move of the power of judgment relies on a preliminary self-reference of the faculties of cognition, namely those faculties the power of judgment alone is entitled to connect and let them match with each other. Determining judgments display just one of the possible employments of the power of judgment in a priori synthesis, as it counts on a given universal. The judgmental connection between the pure concepts of the understanding and the empirical manifold given in intuition leads to the determination of the concepts for the objects of possible experience. Accordingly, possible experience is one of the achievements - one of the most fundamental and relevant - of a priori synthesis. Yet to say that a priori synthesis always takes place in the form of determining judgments is to misunderstand the aims and scope of Kant's critical project.

Analogously, to say that the principle of purposiveness pertains to the reflecting power of judgment is not to say that no purposive self-reference of the power of judgment takes place in the case of determining judgments. The systematic needs of reason worked as ends far before Kant came to identify the principle of purposiveness as such, i.e., as a principle. It has been for Kant unavoidable to understand that reason's purposive activity relies on a transcendental principle for the sole of power that is actually able to let reason's faculties match with each other. The third Critique closes a circle that Kant began to trace almost twenty years earlier, for the power of judgment at once let reason establish its domains and allows their systematic unity. The principle of purposiveness can be but the principle of the power of judgment as such - i.e., as reflecting. Its seemingly exclusive belonging to an allegedly reflecting branch of the power of judgment does not mean that our cognitive determining judgments disregard this principle. Kant's main concern is not to argue for two self-standing functions of the power of judgment but, instead, - as I aim to show in section 3. - to rule out the determining employment of the principle of purposiveness.

In the first Critique, in the introduction to «The Analytic of principles», we find - in embryo, so to say - the very same issue Kant addresses in the third Critique. Where are we to find a principle for the power of judgment? The section «On the Transcendental Power of Judgment in General» $[K r V$, A 132-136 B 172-175 (268-270)] provides no full-fledged answer; yet there is one relevant point. When judging we face the problem of rule-giving, namely the need to find a rule according to which our judgmental rule-giving should take place. The easy way to solve this problem is to state - as Kant does - that the power of judgment is an original talent that has to find its own way. However, the fact that only transcendental logic can be of help in this case - by no means general logic - brings the issue of the power of judgment's employment into play. General logic cannot provide any canon for the lawful employment of the power of judgment for it utterly disregards «all content of cognition». Transcendental logic instead - as it deals with the form of cognition and experience - provides the power of judgment not just with the rule to be applied, but also with the case to which this rule ought to be applied. Does this twofold rule-giving come from outside the power of judgement itself, or should we rather acknowledge that whenever we deal with the lawful employment of the power of judgment we cannot avoid - as a condition - setting 
the functional requirements of the power of judgment as the rule it ought to follow in order to carry out its task?

Kant himself seems to take this path when he makes it clear that, since "the understanding can make no other use of these concepts [the categories] than that of judging by means of them», then "the understanding in general can be represented as a faculty for judging» [KrV, A 68 B 93 (205)]. If in the case of determining judgments the understanding is the power of judgment itself, then the pure concepts of the understanding are but the means the power of judgment employs in order to grant the possibility of experience and cognition. Most importantly, we see that even in the case of determination the functional requirements of the power of judgment constitute its own method. As Longuenesse ([1998]: 196) remarks, in the case of determining judgments the power of judgment «schematizes its reflection».

It is true that the first Critique does not address the point of the power of judgment's reflecting status in the very same way the third Critique does, but this does not prevent us from recognizing the point. Moreover, recognizing this point is one of the most fruitful ways to employ the interpretive framework of the third Critique retrospectively.

Kant's point is not that determining judgments are non-reflecting or non-purposive. Rather, his point is that no determining employment of the principle of purposiveness is lawfully possible. This difference - to which we have to turn now - is key. The normative framework of the understanding alone leads to objective determination, as the categories realizes the unity of the principle of the apperception by making empirical concepts out of the given manifold. This is not the scenario of the reflecting employment of the power of judgment - precisely because there is no universal to be determined. Neither the form of aesthetic representations nor the assumption of an inner finality in natural formations rely on the conditions of determining judgments. The purpose at stake in the principle of purposiveness is just the very employment of the power of judgment itself: not this or that cognitive taking but, rather, the general form of cognition and its system.

The hierarchy between the reflecting and the determining employment of the power of judgment - where the former is the most general form of judging and the latter one of its possible and lawful specifications - accounts for three relevant points. First, the heautonomy of the power of judgment; second, the reciprocity between reflection and purposiveness; third, the illegitimacy of the amphiboly between the reflecting and the determining employment of the principle of purposiveness. As we are going to see, in the case of the amphiboly we would be unable to grant the possibility of the two main achievements of the third Critique: aesthetic and teleological judgments.

\section{AESTHETICS AND TELEOLOGY}

Kant's account of aesthetic judgments of taste further strengthens the reciprocity between reflection and (self-)purposiveness. The very title of $\$$ 35 sounds quite telling: "The principle of taste is the subjective principle of the power of judgment in general» $[K U$, AA 5: $286(167)]$. The claim that the principle of taste is subjective utterly fits with the non-determining employment of the principle of purposiveness. Kant leaves indeed no room open for the determination of the concept of beauty (cf. Tomasi [2017]), for the latter cannot be objective. However, the claim that the principle of taste - a principle of the reflecting power of judgment - is the principle of the power of judgment in general makes sense only insofar as we give up construing a dichotomy between reflection and determination. Kant's words are quite unambiguous. Since «the judgment of taste is not determinable by means of concepts, it is grounded only on the subjective formal condition of a judgment in general. The subjective condition of all judgments is the faculty for judging itself, or the power of judgment» [KU, AA 5: 287 (167), my emphasis].

The non-determinability of the judgment of taste runs parallel to Kant's refusal of the amphi- 
boly between the determining and the reflecting employment of the principle of purposiveness. The former may well be impossible without this to mean that the latter is likewise ruled out. Even more relevant is that Kant stresses that the form of the judgment of taste - a merely reflecting judgment - is in fact the form of a judgment as such. It is, said differently, the form of judging itself. As reflecting, the power of judgment draws a principle out of its own activity. Its end literally mirrors its needs; the final cause is at once an efficient one. We thus see that the aims of the judgments of taste rely on the overarching aims of the power of judgment in general: the lawful synthetic connection of the faculties. While in the case of determining judgments we deal with the synthetic objective unity of the given manifold according to the rules of the understanding (under the aegis of the principle of the apperception), in the case of taste Kant famously appeals to the free play between the imagination and the understanding [KU, AA 5: 287 (167-168)]. The harmonious interplay between these two faculties is the wellspring of the disinterested feeling of pleasure (by no chance this feeling relies on a reflektierte Wahrnehmung, cf. Desideri [2003]: 81-83). In the two different cases at stake, the overarching perspective is still the same, for the power of judgment aims to provide itself with the fundamental conditions for its own lawful employment.

In $\S 58$, which is titled «On the idealism of the purposiveness of nature as well as art, as the sole principle of the power of aesthetic judgment» [KU, AA 5: $346(221)]$, Kant stresses that the free play of the faculties coherently matches with the reflecting status of aesthetic judgments. In the case of taste, we aesthetically aim "to the correspondence of its representation [of the judgment] in the imagination with the essential principles of the power of judgment in general» [KU, AA 5: 347 (221), my emphasis].

In the same paragraph, Kant also cares to distinguish between the idealism and the realism of purposiveness. Kant's ground for this distinction is the same for the distinction between the reflecting and the determining employment of the power of judgment: the illegitimacy of a determining use of the (reflecting) principle of purposiveness. The binary reciprocity between reflection and purposiveness thus gets a third element, namely the idealism of purposiveness itself. Purposiveness works as the principle of the reflecting power of judgment not despite but because of its non-determinability, namely its ideal status. A real purposiveness - an objectively determined purposiveness - would mean an objective principle, i. e., a dogmatic assumption. In this case, we would unlawfully equate the principle of purposiveness and the principles (Grundsätze) of the understanding. By contrast, the purpose of what we may now call reflecting purposiveness - the very idealism of this purposiveness - is instead a mere «intrinsically yet contingently manifested purposive correspondence with the need of the power of judgment in regard to nature and the forms generated in it in accordance with particular laws» $[K U, \mathrm{AA}$ 5: 347 (221-222)]. Aesthetic judgments of taste do nothing but mirror the general heautonomy of the power of judgment - whereby the latter so to say escapes the meshes of objective determination. When judging about beauty we indeed «seek the standard for it in ourselves a priori» [KU, AA 5: 350 (224)].

The same assumptions lay the ground of Kant's teleological judgments ${ }^{2}$. In $\$ 75$, whose title is "The concept of an objective purposiveness of nature is a critical principle of reason for the reflecting power of judgment» [KU, AA 5: 397 (268)], Kant states that to say

that the generation of certain things in nature or even of nature as a whole is possible only through a cause that is determined to act in accordance with intentions is quite different from saying that because of the peculiar constitution of my cognitive faculties I cannot judge about the possibility of those things and their

\footnotetext{
2 This is not to say that aesthetic judgments are teleological judgments, for the latter do not rely on the free harmonious interplay between the imagination and the understanding, nor their universality relies on a feeling. On the distinction between aesthetic and teleological judgments see Pollok (2017): 273-307.
} 
generation except by thinking of a cause for these that acts in accordance with intentions, and thus by thinking of a being that is productive in accordance with the analogy with the causality of an understanding. In the first case I would determine something about the object, and I am obliged to demonstrate the objective reality of a concept that has been assumed; in the second case, reason merely determines the use of my cognitive faculties in accordance with their special character and with the essential conditions as well as the limits of their domain. The first principle is thus an objective fundamental principle for the determining, the second a subjective fundamental principle merely for the reflecting power of judgment, hence a maxim that reason prescribes to it. [KU, AA 5: 397398 (268-269)]

The distinction between the pair objectivity/ determination and the pair purposiveness/reflection - where the former is subordinated to the second - directly follows from these premises. The ground of the distinction at stake lies in the two different employments of the power of judgment. The power of judgment is as such constitutively reflecting. It is merely reflecting as no universal is given. However, when it objectively employs the rules of the understanding with respect to the manifold given in intuition, it is also determining (in its reflection). To claim that the objectivity the determining power of judgment brings about utterly disregards the principle of purposiveness means to claim that Kant provides us with another dichotomy. Even worse, it means to claim that our objectively determining moves are non-purposive - something which would misunderstand the regulative function of the ideas in the first Critique already. Kant proceeds through dichotomies in a number of circumstances but, as shown, it is methodologically wrong to subsume the distinction between determining and reflecting judgments under the genre of the dichotomy. In the case of determination, the power of judgment is, recalling the First Introduction, "also determining» in its reflection [EE, AA 20: 212 (16), my emphasis].

We are thus prevented from conceiving of the determining employment of the power of judgment as disregarding the principle of purposive- ness, for it is precisely because of the constitutive limits of our determining activity that we are required to further assume a purposive order of nature. At the same time, we also see that no determining employment of the principle of purposiveness is lawfully possible. It is worth stressing again that the non-determinacy of the principle of purposiveness (its idealism) is no lack but, rather, its most distinctive mark, namely what actually makes this purposiveness a transcendental principle for the power of judgment. To sum up: 1) determining judgments entail a reflecting moment because of the reflecting status of the power of judgment in general and the principle of purposiveness (the transcendental principle of the power of judgment in general); 2) determining judgments do not make any determining use of the principle of purposiveness (as the determination at stake relies on the categories and the synthetic unity of the apperception).

To assume an objective purposiveness does not mean to turn the subjective (reflecting) principle of purposiveness into an objective one (cf. Steigerwald [2010]: 293). If that were the case, the power of judgment would raise an unlawful dogmatic claim. The principle of purposiveness is either subjective or no principle at all. What distinguishes aesthetic judgments from teleological judgments is no allegedly objective (determining) employment of the principle of purposiveness, but their different scopes. On the one hand, in the aesthetic case, the object of the power of judgment is the form of aesthetic representations themselves. On the other hand, in the case of teleological judgment, the power of judgment takes on natural formations purposively, and consider them as if they were made according to a purposive intention (cf. De Bianchi [2011]: 18-20]. These natural formations are the objects of the power of judgment in the case of teleological judgments.

The purposiveness is here objective in that it deals with actual objects (while aesthetic judgments deal with the subjective form of representations), by no means because it would rely on an objective - i. e., objectively determining - employment of the principle of purposiveness. We are 
necessarily required to assume this purposiveness when dealing with the internal constitution of natural formations, but only as a guide for our judging, insofar as we are thereby able to systematize all empirical laws of nature. This is why teleological judgments are non-determining, for their guiding principle is not objectively determined in actual experience (while this is exactly the case of the categories). In turn, we see that determining judgments are per se unable to accomplish the task of teleological judgments - and this is why the former need the latter. The non-determinacy of the principle of purposiveness is a necessary condition for the reflecting power of judgment to achieve the systematic unity determining judgments are constitutively unable to achieve. By no chance Makkreel ([2006]: 229) refers to this principle as the "reflective principle of systematicity», whereby the purposiveness of nature is «relative to the subject and its rational need for order» (ibidem; see also Tonelli [1958]: 159).

Kant's reference to the peculiar constitution of our cognitive faculties is relevant. Whenever we judge, the power of judgment brings about a synthetic connection of the faculties of cognition. In the case of teleological judgments, this connection is not meant to objectively determine an alleged empirical concept of a natural end or, even worse, the systematic whole of natural laws in concreto. Rather, Kant's point is to provide the power of judgment with a hermeneutical guiding light (cf. Makkreel [1990]: 111-112) while it is busy to investigate an unstable field - for the always increasing multiplicity of nature's laws may well bewilder the activity of the power of judgment itself. By no means "nature as a whole is [...] given to us as organized» [KU, AA 5: 398 (269)].

One last conclusive remark. The idealism of purposiveness counts not only on a negative description, namely as opposed to the realism of purposiveness. Kant also provides us with a positive characterization of the idealism of purposiveness as analogy. The idealism of purposiveness is indeed an analogical one. Already in the First Introduction (section V), Kant writes that «natural laws [...] which are so constituted and related to each other as if they had been designed by the power of judgment for its own need, have a similarity with the possibility of things that presuppose a representation of themselves as their ground" [EE, AA 20: 216 (19), my emphasis]. In the published Introduction (section IV) he further adds that the very same laws have to be taken as if they followed from an overarching understanding who meant to establish those laws as in accordance with our cognitive means [KU, AA 5: 180-181 (67-68)]. Why must we understand these laws in such a purposive way? Because, Kant answers, this is what the power of judgment needs in order to accomplish its task: "to make possible a system of experience in accordance with particular laws of nature» [KU, AA 5: 180 (67-68)]. The expected achievement - the system of all empirical laws of nature (cf. Feloj [2013]) follows from the power of judgment's sole actual ground, that is its at once final and efficient cause: its own method and reflecting purposiveness. Its self-consistency, whose mirror image is the systematic unity of all empirical laws of nature.

When Kant mentions the peculiar constitution of our cognitive faculties, he does not refer to an anthropological or physiological human nature that somehow binds us to assume an undetermined subjective principle because of our allegedly given inability to satisfy needs that would actually exceed our means. In a far more radical and significant way, Kant means that the constitutively reflecting status of the power of judgment binds the power of judgment itself to draw a principle - as a maxim - out of its own use (cf. Siani [2015]: 103). More specifically, a principle driving the power of judgment towards a goal that can be achieved without being thereby objectively determined.

To conclude, the analogical idealism Kant appeals to does not represent a rhetorical means according to which we would discursively make sense of a complex thought. The analogy is indeed the sole logical form by virtue of which it is legitimately possible to conceive of a coherent correspondence between the empirical laws of nature and our judgmental cognitive procedures (cf. La 
Rocca [2011]). As if the former were an analogon of the latter.

\section{REFERENCES}

Allison, H.E., 2012: Reflective Judgment and the Application of Logic to Nature: Kant's Deduction of the Principle of Purposiveness as an Answer to Hume, in Id., Essays on Kant, Oxford University Press, Oxford, pp. 177-188.

Amoroso, L., 2015: Der ästhetische Mensch von Baumgarten bis Schiller, in Asmuth, C., Remmers, P. (eds.), Ästhetisches Wissen, De Gruyter, Berlin-Boston, pp. 83-94.

Anceschi, L., 1972: Considerazioni sulla «Prima Introduzione» alla "Critica del Giudizio» di Kant [1968], in Id., Da Bacone a Kant. Saggi di estetica, Il Mulino, Bologna, pp. 175-221.

Barale, M., 1992: Critica del giudizio e metafisica del senso, "Archivio di storia della cultura" 5, pp. 65-86.

De Bianchi, S., 2011: Kant's Concept of the Technique of Nature in the Critique of the Power of Judgment, "Kant e-Prints" 6 (1), pp. 12-28.

Desideri, F., 2003: Il passaggio estetico. Saggi kantiani, Il Melangolo, Genova.

Feloj, S., 2013: Towards an Alternative: Crisis of the System or Mediation between Nature and Freedom? The Concept of Einheit der Erfahrung in the Erste Einleitung, in Bacin, S., Ferrarin, A., La Rocca, C., Ruffing, M. (eds.), Kant und die Philosophie in weltbürgerlicher Absicht. Akten des XI. Internationalen Kant-Kongresses, De Gruyter, Berlin-Boston, Bd. 1, pp. 535-542.

Ferrarin, A., 2015: The Powers of Pure Reason. Kant and the Idea of Cosmic Philosophy, The University of Chicago Press, Chicago-London.

Fugate, C.D., 2014: The Teleology of Reason. A Study of the Structure of Kant's Critical Philosophy, De Gruyter, Berlin-Boston.

Garroni, E., 1998²: Estetica ed epistemologia. Riflessioni sulla "Critica del giudizio" di Kant, Edizioni Unicopli, Milano.

Henrich, D., 1992: Kant's Explanation of Aesthetic Judgment, in Id., Aesthetic Judgment and the
Moral Image of the World. Studies in Kant, Stanford University Press, Stanford (CA), pp. 29-56.

Kant, I., 1781 $1-1787^{2}$ : Critique of Pure Reason, transl. and ed. by P. Guyer, A. W. Wood, Cambridge University Press, Cambridge, 1998.

Kant, I., 1790: Critique of the Power of Judgment, transl. by P. Guyer, E. Matthews, ed. by P. Guyer, Cambridge University Press, Cambridge, 2000.

La Rocca, C., 2011: Formen des Als-Ob bei Kant, in Dörflinger, B., Kruck, G. (eds.), Über den Nutzen von Illusionen. Die regulativen Ideen in Kants theoretischer Philosophie, Olms, Hildesheim-Zürich-New York, pp. 29-45.

Longuenesse, B., 1998: Kant and the Capacity to Judge. Sensibility and Discursivity in the Transcendental Analytic of the Critique of Pure Reason. Translation by C. T. Wolfe, Princeton University Press, Princeton (NJ).

Makkreel, R.A., 1990: Imagination and Interpretation in Kant. The Hermeneutical Import of the Critique of Judgment, University of Chicago Press, Chicago-London.

Makkreel, R.A., 2006: Reflection, Reflective Judgment, and Aesthetic Exemplarity, in Kukla, R., (ed.), Aesthetics and Cognition in Kant's Critical Philosophy, Cambridge University Press, Cambridge, pp. 223-244.

Nuzzo, A., 2005: Kant and the Unity of Reason, Purdue University Press, West Lafayette (IN).

Pollok, K., 2017: Kant's Theory of Normativity. Exploring the Space of Reason, Cambridge University Press, Cambridge.

Siani, A.L., 2015: Kants ästhetische Urteilskraft als nicht-ästhetisches Wissen und das Ende des modernen Subjekts, in Asmuth, C., Remmers, P. (eds.), Ästhetisches Wissen, De Gruyter, Berlin-Boston, pp. 95-109.

Steigerwald, J., 2010: Natural Purposes and the Reflecting Power of Judgment: The Problem of the Organism in Kant's Critical Philosophy, "European Romantic Review” 21 (3), pp. 291-308.

Teufel, T., 2012: What Does Kant Mean by 'Power of Judgement' in his Critique of the Power of Judgement?, "Kantian Review” 17 (2), pp. 1-30. 
Tomasi, G., 2017: L'oggettivismo debole di Kant in estetica, "Estudos Kantianos" 5 (1), pp. 81-98.

Tonelli, G., 1958: Von den verschiedenen Bedeutungen des Wortes Zweckmäßigkeit in der Kritik der Urteilskraft, "Kant-Studien" 49 (1-4), pp. 154-166.

Zuckert, R., 2007: Kant on Beauty and Biology. An Interpretation of the Critique of Judgment, Cambridge University Press, Cambridge. 